Sección general 



\title{
Participación política del sindicalismo colombiano. Un estudio introductorio*
}

\author{
Marco Fidel Agudelo CANo*
}

Artículo recibido: 11 de julio de 2012

Artículo aprobado: 18 de noviembre de 2013

Doi: dx.doi.org/10.12804/desafios26.1.2014.07

Para citar este artículo: Agudelo Cano, M. F. (2014). Participación política del sindicalismo colombiano. Un estudio introductorio. Desafios, 26 (1), 267-296. doi: dx.doi.org/10.12804/ desafios26.1.2014.07

\section{Resumen}

El sindicalismo como institución es cuestionado desde la sociedad civil por su insuficiente capacidad de articulación social, su limitada fuerza gremialista y su deficiente representación de los intereses públicos y sociales de los trabajadores y del conjunto de la sociedad. Desde este panorama, los escenarios de representación política podrian constituir una alternativa para el fortalecimiento de su objeto en la sociedad, una estrategia para la conservación de sus actuales reivindicaciones o una acción que evite su desaparición. Este articulo explora el papel, la importancia, la representación politica y la participación del sindicalismo en cargos de elección popular en Colombia, tras reconocer la tendencia de su desvanecimiento social como colectividad en la última década, aunque representado individualmente por medio de algunos dirigentes en escenarios de toma de decisión.

Palabras clave: ciudadanía laboral, sindicalismo, movimiento social de los trabajadores, partidos políticos, participación electoral

* Este artículo es producto de la investigación finalizada "Estudio introductorio acerca de la participación política y electoral de dirigentes sindicales en cargos de elección popular en Colombia entre 2002-2010", realizada en el marco de la especialización en Ciencia Política de la Universidad Nacional de Colombia, sede Medellín, en 2011. Esta investigación está siendo ampliada en su segunda fase.

** Psicólogo, especialista en Ciencia Política, de la Universidad Nacional de Colombia. Investigador de la corporación Transparencia por Colombia, capítulo Colombia. Bogotá, Colombia. Correo electrónico: agudelo.cano@gmail.com 


\title{
Political Participation of Colombian Unionism. An Introductory Study
}

\begin{abstract}
Unionism, as an institution, is questioned by civil society for its insufficient social articulation, the limited unionist force and the underrepresentation of the public and social interests of workers and society as a whole. Seen from this perspective, the scenarios of political representation could be an alternative for strengthening its purpose in society, and a strategy for the preservation of its contemporary claims and action in order to prevent the demise of unionism. This article explores the role, importance, political representation and participation level of union leaders in elections in Colombia, thereby recognizing the trend during the last decade of a socially diminished unionism, but individually represented by some leaders in some decision-making scenarios.
\end{abstract}

Key words: labor citizenship, unionism, social movement of workers, political parties, electoral participation

\section{Participação política do sindicalismo colombiano. Um estudo introdutório}

\begin{abstract}
Resumo
O sindicalismo, como instituição, é questionado desde a sociedade civil por sua insuficiente capacidade de articulação social, por sua limitada força gremial e por sua deficiente representação dos interesses públicos e sociais dos trabalhadores e do conjunto da sociedade. Desde este panorama, os cenários de representação politica poderiam constituir uma alternativa para o fortalecimento de seu objeto na sociedade, uma estratégia para a conservação de suas atuais revindicações ou uma ação que evite sua desaparição. Este artigo explora o papel, a importância, a representação política e viveis de participação do sindicalismo em cargos de eleição popular na Colômbia, a reconhecendo como tendência na última década, de seu desvanecimento social como coletividade ainda representado individualmente através de alguns dirigentes em alguns cenários de tomada de decisão.
\end{abstract}

Palavras- chave: cidadania laboral, sindicalismo, movimento social dos trabalhadores, partidos políticos, participação eleitoral 
¿Qué ha representado para el sindicalismo colombiano el acceso de sus dirigentes a cargos de elección popular en la última década? Estar en estos escenarios se convierte para el sindicalismo en alternativa e instrumento que, ante la pérdida de poder gremial en las negociaciones con el Estado o con los empleadores, protege en temas del trabajo y de la política social; además, porque son estos ámbitos los eslabones articuladores del ejercicio socialdemócrata del sindicalismo con otros sectores y movimientos sociales y de la expresión política de la ciudadanía laboral. Como complemento, permite observar cómo se posiciona el sindicalismo en el marco de la política nacional, en el sistema electoral, en el escenario de informalidad y de flexibilización laboral, de pérdida de derechos y de trasformación del sentido del trabajo como condición constitutiva del sujeto social.

Contestar a esta cuestión requiere reconocer el peso social y político del sindicalismo en Colombia, su construcción histórica y su capacidad de respuesta frente a las necesidades de las colectividades de trabajadores colombianos y frente a los planes de acción y las estrategias políticas implementadas para participar en los espacios de decisión política en el Gobierno del país durante un siglo de historia.

El sindicalismo como institución es cuestionado desde la sociedad civil por su insuficiente capacidad de articulación social, su limitada fuerza gremialista y su deficiente representación de los intereses públicos y sociales de los trabajadores. Dado lo anterior, los espacios de representación política (Senado de la República, Cámara de Representantes, Asambleas departamentales, Concejos municipales, Gobernaciones y Alcaldías) podrían constituir una alternativa para el fortalecimiento de su objeto en la sociedad, una estrategia para la conservación de sus actuales reivindicaciones o una acción desesperada que evite su desaparición.

Entonces, cuando se habla de la representación política de los líderes sindicales, se nombra a aquellos que, por el ejercicio de su actividad sindical, se forman políticamente, acceden a escenarios de dirigencia y liderazgo, construyen una base electoral local o nacional, sectorizada o intergremial, elaboran un discurso social y político y se articulan a planes gremiales o partidistas. Por ello, este trabajo es un frente de 
investigación poco explorado por los partidos políticos tradicionales, por las centrales sindicales y por el conjunto de la población académica interesada en los temas laborales y electorales del país. A su vez, indaga acerca del aporte histórico del movimiento social de los trabajadores a la cultura política y partidista colombiana, visibiliza el desarrollo empírico de los trabajadores en el ejercicio de la ciudadanía laboral y reconoce la preocupación de este movimiento social por los temas de interés público, el desarrollo local, la relación entre trabajo, trabajadores y agendas locales para trascender las esferas de lo estrictamente laboral, sindical y gremial, además de reconocer el accionar político del sindicalismo.

Este artículo centra su atención en la participación política del sindicalismo en Colombia, mediante la articulación de líderes sindicales con partidos políticos para alcanzar cargos de elección popular. En este sentido, aunque se presenta un breve recorrido por los logros laborales alcanzados en el siglo XX, su alcance está delimitado por los eventos electorales del período 2002-2010, que mostró un sindicalismo interesado en participar en política electoral.

\section{Conquistas laborales y políticas de los trabajadores}

En 1909 se expidió la primera personería jurídica a una organización obrera y artesanal por parte del Gobierno nacional. Es probable que ya existieran otras agrupaciones de este tipo sin personería jurídica, dado que para entonces no era obligatorio ese reconocimiento legal para actuar. En adelante, cada año aparecieron nuevos sindicatos, sobre todo en las primeras décadas del siglo XX (Urrutia, 1996).

Factores como el proceso de industrialización, la difusión de ideas de avanzada que venían de Europa, de la Revolución Mexicana y del Movimiento Obrero en Estados Unidos, el aumento de la densidad poblacional de las ciudades, las condiciones de trabajo precarias para los obreros, la aparición de algunas empresas grandes — como las de navegación fluvial y algunos ferrocarriles - pusieron en marcha las inquietudes obreras y la formación del sindicalismo a inicios del siglo XX. Incluso en 1910 varias asociaciones obreras y artesanales trataron de formar un Partido Obrero Colombiano (Poveda, 2005, p. 97). 
Lo que se conoce como prestaciones sociales para empleados colombianos comenzó a establecerse en el gobierno de Rafael Reyes y, aunque hoy parezca irrelevante, para el momento significó un avance progresista. La Ley 29 de 1905 creó la pensión de jubilación para los empleados públicos y la Ley 12 de 1907 instituyó esa misma prestación para magistrados y jueces.

El movimiento obrero asumía y expresaba una posición reivindicativa, como una acción claramente política. En 1910, el país vio sorprendido la primera gran huelga con repercusiones nacionales organizada por sindicatos de los vapores y los braceros en el puerto fluvial de Barranquilla, donde se reclamaron mejores condiciones de trabajo.

Algunos gobernantes y parlamentarios pronto entendieron la necesidad de responder con inteligencia a las reivindicaciones demandadas por el naciente y dinámico movimiento obrero. Así, en 1913, la Ley 114 extendió la jubilación a maestros oficiales de las escuelas primarias. En 1915, la Ley 57 estableció las indemnizaciones por accidentes de trabajo a obreros de bajos salarios. En 1918, la Ley 46 obligó a los municipios a destinar un $2 \%$ de su presupuesto a la construcción de vivienda para los obreros. Las Leyes 78 de 1919 y 21 de 1920 consagraron y reglamentaron el derecho a la huelga. Esta última ordenó arbitrar los conflictos de trabajo y prohibió los paros en las empresas de servicio público (Poveda, 2005, p.151).

En 1916 se proponía como agenda para un congreso del Partido Obrero, que intentaba fundarse, los siguientes puntos: 1) organización de los obreros; 2) descanso dominical remunerado; 3) legislación obrera; 4) trabajo de la mujer; 5) mutualidades obreras; 6) caja de ahorros; 7) habitaciones para los obreros; 8) bibliotecas, institutos y escuelas; 9) defensa contra el alcohol y la miseria, y 10) protección y cooperación (Poveda, 2005, p.152).

Para la tercera década del siglo XX, el gobierno de Olaya Herrera inauguró una época de reformas laborales. Varias fuerzas socioeconómicas y políticas determinaron la necesidad de esta nueva política reformista; 
entre ellas, las siguientes fueron las principales determinantes de un nuevo trato de la clase trabajadora:

- El acelerado aumento del número de trabajadores industriales.

- El proceso de sindicalización creciente y el ejercicio de los sindicatos por una fuerte vocería para lograr nuevos derechos para los trabajadores.

- Las nuevas ideas progresistas adoptadas por el Partido Liberal para acercarse al socialismo democrático, que venían desde 1904 cuando así lo reclamó el general Rafael Uribe Uribe, quien entonces dirigía ese Partido.

- El crecimiento de partidos pequeños, pero muy activos, de tipo social-demócrata y de tipo comunista-marxista.

- La influencia remota —en tiempo y espacio—y sensible de la Revolución Bolchevique en Rusia en 1917.

Estos y otros factores encontraron atención efectiva en el Gobierno del momento, traducida en leyes aprobadas por el Congreso:

- Ley 72 de 1931 que, con su Decreto reglamentario 1278 del mismo año, mejoró las condiciones del descanso dominical remunerado para los trabajadores asalariados.

- Ley 133 de 1931, que definió los accidentes de trabajo y puso a cargo del empleador la atención médica y la obligación de indemnizar al trabajador.

- Ley 1 de 1932 que, con su Decreto reglamentario 1431 de 1932, estableció la obligación para las empresas ferroviarias de conceder pensión vitalicia de jubilación a cada trabajador cuando este cumpliera veinte años de trabajo y que además completara 55 años de edad para hombres y 50 para mujeres.

- Ley 133 de 1931 y el Decreto 800 de 1932, que instituyeron la obligación para todos los empleadores de constituir y pagar un seguro de vida de sus trabajadores.

- Ley 134 de 1931 y los Decretos legislativos 874 y 1108 de 1932, que estatuyeron las sociedades cooperativas en Colombia y su reglamentación y les dieron estímulos tributarios. Se trataba de crear 
e impulsar un gran instrumento de mejoramiento económico al servicio de los trabajadores y de las incipientes clases medias.

- Ley 83 de 1931, la cual dio carta de naturaleza al sindicato gremial de trabajadores, garantizó y ordenó el derecho a la sindicalización de los trabajadores privados y oficiales, avaló y reglamentó el derecho a la huelga y sentó las bases sobre el arreglo de conflictos laborales.

- Ley 129 de 1931, que aprobó las convenciones internacionales - recién firmadas - sobre universalización de los principios generales del trabajo.

- Artículo 15 del Decreto 992 de 1930, que instauró el derecho de los aparceros y arrendatarios al reconocimiento y al pago de toda mejora realizada en el predio con conocimiento previo del propietario.

- A comienzos de 1934, el gobierno de Olaya expidió el célebre Decreto 895, que estableció la jornada laboral de ocho horas diarias, en respuesta a una de las más importantes aspiraciones de los trabajadores colombianos.

- Decreto 711, que creó el Banco Central Hipotecario como banco del Estado para remplazar a los bancos hipotecarios particulares que habían quebrado por la crisis, dedicado a financiar la construcción de vivienda.

- Ley 10 de 1934, que señaló prestaciones para empleados y trabajadores, como vacaciones remuneradas cada año, auxilio en dinero en caso de enfermedad y cesantías por despido injusto. Además, incorporó el contrato de trabajo en la legislación nacional.

La regulación laboral progresista se mantuvo hasta fines de los años cuarenta con una legislación laboral bastante avanzada para su época, que fue duramente resistida por algunos grupos reaccionarios de pequeños propietarios y empresarios rurales y urbanos.

Para el gobierno de López Pumarejo era prioridad el fortalecimiento del naciente movimiento sindical, mediante el apoyo a los obreros urbanos y campesinos y sus reivindicaciones. Prueba de ello fue la rapidez con la que proliferaron las asociaciones gremiales, título designado a los sindicatos de trabajadores a partir de 1934. Este Gobierno fue partidario de impulsar la industrialización del país dentro de un 
criterio de equilibrio social. En el período 1934-1939, la industria tuvo una de sus épocas de mayor auge del siglo (Poveda, 2005, p. 254). Al tiempo que se fortalecía el sindicalismo, se generalizaba la legislación laboral y se robustecía el cooperativismo.

Más adelante, Colombia acogió la Declaración Universal de Derechos Humanos de 1948, cuyo Artículo 23 expresa:

1. Toda persona tiene derecho al trabajo, a la libre elección de su trabajo, a condiciones equitativas y satisfactorias de trabajo y a la protección contra el desempleo.

2. Toda persona tiene derecho, sin discriminación alguna, a igual salario por trabajo igual.

3. Toda persona que trabaja tiene derecho a una remuneración equitativa y satisfactoria que le asegure, así como a su familia, una existencia conforme a la dignidad humana y que será completada, en caso necesario, por cualquier otro medio de protección social.

4. Toda persona tiene derecho a fundar sindicatos y a sindicalizarse para la defensa de sus intereses.

Algunas de estas consideraciones fueron acogidas por el gobierno de Ospina, quien estableció, por norma, el salario mínimo. Este equivalía al mínimo ingreso monetario para garantizar el sustento del trabajador y se aplicó desde el 1 de enero de 1950.

Luego, acuerdos como el Pacto Internacional de Derechos Económicos, Sociales y Culturales, en 1966, reforzaron el derecho al trabajo y a la formación técnica y profesional, así como las libertades políticas, entre las cuales estaba el sindicalismo.

Por último, es necesario mencionar la inclusión del derecho al trabajo en el Artículo 25 de la Constitución Política de 1991: "El trabajo es un derecho y una obligación social y goza, en todas sus modalidades, de la especial protección del Estado. Toda persona tiene derecho a un trabajo en condiciones dignas y justas". Esto no solo cambió la institucionalidad del país y las reglas de juego entre empresarios y trabajadores, sino que derivó una nueva normativa sustentada en esta norma superior. 
Este recorrido por las reivindicaciones normativas en materia laboral y sindical es necesario para reconocer las apuestas estratégicas que el movimiento propone en la actualidad y los cambios estructurales a los que ha estado sometido en las últimas décadas, entre ellas, sus formas organizativas y su apuesta política. De tener una base sindical con altos índices de analfabetismo y una dirigencia centrada en las exigencias salariales, contractuales y propias del proceso de producción o de las necesidades en seguridad social de los trabajadores, se avanza en estrategias educativas que cualifican política y técnicamente al conjunto de los trabajadores, en particular a los sindicalizados, como una respuesta a las demandas permanentes de la sociedad colombiana por la internacionalización del sindicalismo y de las trasformaciones en el mundo del trabajo y de los trabajadores.

\section{Acciones políticas del sindicalismo}

Se comprende por partido político a una organización estable que tiene por objetivo principal la conquista y ejercicio del poder político, con el fin de organizar la sociedad y el Estado de acuerdo con la ideología e intereses sociales que representa (Calero, 1985). Estos surgen en respuesta a la demanda de las colectividades — sectores organizados para acceder al poder- y a la suma de voluntades y acuerdos. Se materializa en el voto por un determinado programa de Gobierno; así se convierte en mediador entre la sociedad y el Gobierno en un sistema democrático $^{1}$ en donde hay representatividad y consenso, ello es, el apoyo desde la sociedad para imponer las acciones de Gobierno. Los partidos trabajan por la estructuración del voto, la integración y movilización de las masas, el reclutamiento de líderes políticos, la alianza con élites de poder, la elaboración de las políticas públicas a desarrollar y la integración de los intereses ciudadanos.

\footnotetext{
1 Una democracia es un sistema en el cual el pueblo puede cambiar sus gobernantes de una manera pacífica y al Gobierno se le confiere el derecho de gobernar porque así lo quiere el pueblo. En palabras de Sartori (1992), la democracia es una abreviación que significa liberal democracia y distingue tres aspectos: 1) la democracia como principio de legitimidad; 2) la democracia como sistema político, y 3) la democracia como ideal. La democracia como sistema político tiene relación con la titularidad del poder y el ejercicio de este, cara a cara en escenarios pequeños y por medio de la democracia representativa en poblaciones numerosas.
} 
Se afirma que una agrupación adquiere estatus de partido cuando reúne las siguientes características: a) una estructura más duradera que sus dirigentes, b) una cobertura y comunicación nacionales, con afiliados en el territorio nacional, c) busca apoyo popular para sus propuestas, d) la adhesión será en torno a una doctrina y a un programa (Sánchez, 1994, p.12).

En palabras de Antonio Gramsci (1985), los partidos políticos tienen un pie en la sociedad donde realizan sus actividades cotidianas y otro en el Estado, para hacer posible que estos intereses de la sociedad civil se materialicen en políticas públicas articuladas a la agenda programática como demandas políticas, en los diferentes escenarios de la vida pública —ellos son Alcaldías, Concejos, Gobernaciones, Asambleas departamentales, Congreso de la República y Presidencia y, en general, en las instituciones estatales-.

Por su parte, el sindicalismo se ha considerado como la estructura organizativa que representa los intereses de los trabajadores en el ámbito empresarial y ante el Estado. En su extensión se comprende por sindicato a la organización relacionada con la actividad laboral asalariada de los trabajadores y, con ella, la concentración productiva, la implementación tecnológica, la organización del trabajo y las relaciones laborales, es decir, las culturas del trabajo; además, la estructura del mercado de trabajo, su distribución por ramas y ocupaciones en la economía, la estructura organizacional de dichos sindicatos, las ideologías dominantes y las formas más amplias de subjetividad de sus agremiados, las demandas y las formas de lucha de estas organizaciones y el tipo de relación entre sindicatos, partidos, empresas y Estado (De la Garza, 2003).

En los regímenes democráticos contemporáneos, los partidos políticos son la pieza más importante del engranaje político, pues son canales fundamentales de vertebración social, expresión de los diferentes intereses de la sociedad civil a la cual representan y guías indispensables en la solución de problemas de interés general. 
La adscripción regularmente hereditaria que conformaron los partidos políticos tradicionales en Colombia estuvo marcada por la exclusión e intolerancia frente al otro, lo que signó la confrontación partidista con el símbolo de la violencia. Evidencia de ello fueron las permanentes guerras civiles propiciadas en el pasado desde los partidos tradicionales y de estos en relación con la izquierda y sus incipientes formas organizativas.

En términos del progreso histórico del sindicalismo, se muestra cómo a mediados del siglo XIX estos pasaron de ser organizaciones ilegales a ser fuerzas políticas junto a los partidos que contribuyeron en la construcción de instituciones centrales en las sociedades capitalistas modernas y a ser parte integrante del funcionamiento institucional de los sistemas de relaciones industriales en el siglo XX en Norteamérica y Europa. Para Colombia, la relación sindicatos-partidos políticos surge a inicios del siglo XX, en clave de reivindicaciones laborales, de un lado y apoyo electoral de numerosas poblaciones, del otro.

Es de anotar que, a partir de 1980, el sindicalismo colombiano entró en crisis — que se mantiene hasta la actualidad — e incierta reestructuración interna y externa, pese a haber participado en correlación con partidos políticos y, en algunos casos, funcionar como tal. "Los partidos obreros fueron el resultado de reivindicaciones gremialeslaborales inmediatas (programa mínimo) y transformaciones radicales (programa máximo). Lo dominante no era la composición social sino la ideología de clase" (Sánchez, 1994, p.12). Para Colombia, las reivindicaciones de Programa Mínimo fueron un éxito, sobre todo en la primera parte del siglo XX; el Programa Máximo continúa siendo una búsqueda para el sindicalismo.

Así, para Colombia se identifican algunas causas del debilitamiento del sindicalismo en relación con la participación política, la trasformación del Estado benefactor al Estado liberal; la acumulación de capital desde modelos de producción basados en la intensificación del trabajo y el bajo salario; una clase trabajadora diversa situada en la industria y el sector servicios carente de identidad con el trabajo, la empresa o el 
sindicato; un sistema de relaciones de trabajo transformado que ha debilitado la influencia sindical en las políticas del Estado; la flexibilización de grandes contratos colectivos; las culturas empresariales que fabrican un concepto unilateral, no compartido, de propiedad y dirección y del trabajo como factor de producción y del empleo como favor; culturas sindicales autoritarias en la vida interna de las organizaciones obreras y culturas obreras que van del favorecimiento de los intereses de la empresa en detrimento de los derechos sindicales al instrumentalismo sin identidad como gremio; una creciente cultura antisindical expresada en hechos de violencia desde actores armados vinculados con empresarios o el mismo Estado, entre otras.

Cuando se habla de la historia política del sindicalismo, es necesario relacionar dos condiciones estructurales que limitaron su constitución y su desarrollo político: primero, los partidos tradicionales ${ }^{2}$ cooptaron al naciente movimiento de los trabajadores y lo incorporaron a las filas del liberalismo mediante una relación instrumental: el partido obtiene y garantiza su base electoral con los trabajadores a cambio de algunas garantías laborales tramitadas en el Congreso, con lo que desestimula y limita la unidad partidista y la estructuración política del sindicalismo, iniciado en 1930 bajo el plan de Gobierno la "Revolución en Marcha", de López Pumarejo. Segundo, la corporatización de los trabajadores de inicio de siglo en la Federación Nacional de Cafeteros, lo que evitó su agremiación sindical y su conformación como clase trabajadora.

Comprender las limitaciones del sindicalismo como actor político posibilita asimilar su accionar actual. Así, en las múltiples carencias del sindicalismo, propone Bernal (2005):

Es clave que el movimiento sindical le hable y abra alternativas de organización a los millones de desempleados, de subempleados, de trabajadores informales, de mujeres y jóvenes que tienen que vender su fuerza de trabajo en condiciones indignas. El mundo del

\footnotetext{
2 Las convenciones del liberalismo y conservatismo periódicamente reúnen a más de 1.000 delegados, de los cuales la representación sindical no excede los treinta que no constituyen unidad política por ser nombrados de las centrales regionales.
} 
trabajo continuará a pesar de los procesos de globalización y de transnacionalización del capital y ello establece los fundamentos materiales para la organización de los trabajadores, el capital necesita de ellos y estos necesitan agruparse, relacionarse. Esta sigue siendo la base de un movimiento sindical y laboral, de lo que se trata es de ser más creativos y audaces para favorecer los niveles de organización (2005, p.158).

Sugiere el autor que para este movimiento es de vital importancia, la profundización de la democracia. Si se está trabajando por la democracia en la sociedad, el sindicalismo debe ser ejemplo de ello en su forma de actuar. Es necesario abrirse a otras agendas, a otros grupos sociales y a otros procesos. Trascender los intereses gremiales e incluirse en otras acciones y discusiones que vuelva a legitimarlo como movimiento social y no solo como movimiento de trabajadores, que es a lo que se ha visto abocado en su reducción sistemática, pues el sindicalismo ha sido reconocido históricamente por su actitud propositiva y responsable frente a la formación de ciudadanía, la ampliación del tejido social, la formación de una sociedad más plural y menos patriarcal, los aportes a la deliberación pública y a la concertación social, la participación en la planeación del desarrollo y a la formulación de las políticas públicas, la labor de veeduría y control ciudadano y la participación en los planes y agendas de los procesos de pacificación del país (Bernal, 2005, p. 159).

[...] la participación política es aquel conjunto de actos y de actitudes dirigidos a influir de manera más o menos directa y más o menos legal sobre las decisiones de los detentadores del poder en el sistema político o en cada una de las organizaciones políticas, así como en su misma selección, con vistas a conservar o modificar la estructura (y por lo tanto los valores) del sistema de intereses dominantes (Bartolini, 1988, p. 180).

Es claro entonces que los ciudadanos con mayor capacidad de incidencia en la elección de políticas y de quienes las guiarán serán aquellos activos y organizados, porque mediante mecanismos como la presión, la información, el control y el seguimiento visibilizan un 
poder que debe ser tenido en cuenta al momento de elegir a aquellos que detentan el poder.

Esta es una consecuencia directa de la participación política de los ciudadanos activos, relacionada con las medidas de presión históricas (la huelga, el paro, las mesas de negociación) que los trabajadores han ejercido y que han dado como resultado acciones políticas traducidas en normas laborales o en garantías directas. "La actividad política se caracteriza por relaciones que se producen de formas, modos, con frecuencias e intensidades distintas entre individuos, grupos, asociaciones e instituciones. Estas relaciones se clasifican y analizan fundamentalmente dentro de la categoría de participación política" (Bartolini, 1988, p. 179), desarrollada por los trabajadores desde antes de nacer el sindicalismo. Si bien es cierto que una cosa es el gremio y otra el partido político, también lo es que en los gremios y en los movimientos sociales hay lucha política, que no es otra cosa que la lucha por la orientación en cuanto a la definición de principios, objetivos, proyecto histórico, plataforma de lucha y programa de trabajo (López de Mesa y Monsalve, 1991, p. 105).

A partir de la llamada Revolución Industrial, el movimiento obrero se ha caracterizado por la tendencia de los trabajadores a agruparse en organizaciones estables y distribuidas profesionalmente, dirigidas a defender sus intereses, reivindicar los derechos civiles y políticos ${ }^{3} \mathrm{y}$ luchar por las aspiraciones colectivas de los mismos.

Desde el punto de vista de sus fines, los trabajadores organizados han propugnado por dos grandes intereses: los denominados fundamentales, conformados por la búsqueda de mejores condiciones de trabajo, elevación de la calidad de vida, defensa de sus intereses profesionales y asistencia a los miembros del sindicato y los llamados intereses accesorios: que van desde la participación de los trabajadores en la gestión de las empresas hasta la trasformación de las estructuras económicas

\footnotetext{
3 Ver para Colombia las sentencias de la Corte Constitucional T-719 de 2003 y T-1037 de 2006.
} 
y sociales del Estado y pasan por la colaboración y el apoyo temporal en el impulso de programas de empleo.

En el desarrollo del Estado liberal, los trabajadores han adoptado diversas formas participativas en su relación con los entes gubernamentales y privados: negociación colectiva sobre condiciones de empleo y escalas salariales; disposiciones de tipo económico, sobre defensa de la estabilidad laboral y la supervivencia de las instituciones públicas ante las políticas privatizadoras de los Gobiernos, entre otras. Con la implementación de las medidas tomadas por el Consenso de Washington en el marco del pago de la deuda externa para los países latinoamericanos y del proceso de apertura económica en Colombia, se abrió un campo de trasformación y dinamización de los actores internos y externos en el marco del libre mercado y de la flexibilización del trabajo como modelo de producción y de las relaciones laborales, todo ello en respuesta a las necesidades identificadas externamente de generar mayores índices de control interno político y social en Colombia a razón de ser identificado como un Estado débil.

Dentro de su papel de control político, afirma Pizarro, las ventajas de un esquema de oposición son claras:

Primero, permite la canalización de los desacuerdos por la vía institucional. Segundo, sirve para estrechar los vínculos entre los electores y los elegidos. Tercero, aumenta la fiscalización, lo cual puede redundar en una reducción de la corrupción y de la ineficacia de la gestión pública. Cuarto, es un instrumento para fortalecer los partidos y la oposición. Y finalmente, el gobierno se ve obligado a centrar su gestión en su programa y no en el resultado de simples pactos burocráticos (1997, citado en Giraldo 2003, p. 22).

Así, la construcción de la dimensión de relaciones entre el dirigente y los dirigidos consiste en gobernar y administrar el poder y, en la oposición, es vigilar, presionar, auditar y solicitar rendición de cuentas a los gobernantes. Entonces, es necesario tener capacidad de gestión cuando administra el poder e independencia cuando fiscaliza desde la oposición (Giraldo, 2004, p. 163). Una sociedad que se piensa de- 
mocrática ha de encontrar en el sindicalismo político un aliado o, en su defecto, un actor representativo de un conjunto poblacional que reclama ciudadanía laboral y, por lo tanto, representación política.

Bobbio (1986) afirma que hay que defender la democracia a pesar de sus vicios y por sus virtudes: la tolerancia, la no violencia, el libre debate de las ideas y el ideal de la fraternidad, bajo el criterio de la igualdad entre los individuos, condición fundamental de la libertad de las personas. En un Estado débil se limita a garantizar la materialización de la libertad para los trabajadores. El gran debate que hoy se esgrime en la esfera de los Estados seguros está en el escenario, no del Estado liberal, sino de la sociedad civil en tanto es allí donde el vínculo con el trabajo se está manifestando; es en esta donde se concretan las nuevas realidades de los trabajadores en democracias en transición y donde los Estados desregularizan las relaciones de derechos, entre ellas, las del trabajo y las de libertad sindical para cada ciudadano, como condición fundamental para la participación y la acción política.

Un elemento progresista, civilista y moderno de las sociedades consiste en agruparse para gobernarse y limitar al estado de naturaleza propio de las comunidades barbáricas, donde la imposición de la fuerza era el elemento común y diferenciador en las jerarquías internas de los grupos. Además de la condición y el ejercicio de lo público del sindicalismo, se manifiesta su posición ideológica como condición política. Tal ideología se vincula con apoyo a la institucionalidad o con rechazo y cuestionamiento al régimen; esto implica varios elementos: 1) una posición como grupo diferenciada del resto de la sociedad; 2) el reconocimiento de un tercero ante el cual mediar y exigir; 3) la construcción de propuestas que exceden los límites de lo gremial, de lo laboral y de lo económico, pues el sindicalismo no es solo una organización de trabajadores con necesidades administrativas, y 4) permanencia y estabilidad ideológica. Se aprecian los siguientes componentes como condiciones necesarias en la identificación de lo político del sindicalismo: reconocimiento del ser y del hacer del sindicalismo en la política; ejercicio de la libertad sindical como conquista de la política organizada del sindicalismo y muestra concreta de la política como acción; organización social y regulatoria del trabajo como plataforma 
del sindicalismo; ejercicio del autogobierno organizacional desarrollado en tres siglos; dominio público de sus acciones como naturaleza política; identidad ideológica trasversal en su historia y distanciamiento ideológico del Estado.

Para este propósito, Warren (2003, p. 22) plantea que los componentes necesarios en una concepción de la política debería: a) ayudar a clarificar nuestros intereses normativos en política; b) articular las visiones cotidianas de política, en especial las dirigidas a los cambios en los dominios de la política así como a sus límites variables y posibilidades normativas, y c) definir el ámbito de la política de modo que resulte suficientemente diferenciado como para que quede justificada la definición.

Dice Bobbio que:

[...] sin libertades civiles, como la libertad de prensa y de opinión, como la libertad de asociación y de reunión, la participación del pueblo en el poder político es un engaño; pero sin participación popular en el poder, las libertades civiles tienen bien pocas probabilidades de durar (Bobbio, Matteucci y Pasquino, 1993, p. 117).

\section{Estrategias, actores y acciones contra el sindicalismo colombiano}

En la última década se han incrementado progresivamente las formas de vulneración complementarias propias del conflicto sociopolítico del país y del accionar de los actores violentos como el desplazamiento forzado, el hostigamiento, los atentados con o sin lesiones, el allanamiento ilegal, la tortura, el homicidio de familiares y el secuestro. Ante estas manifestaciones concretas de violencia hacia el ejercicio político del sindicalismo, la libertad de sus dirigentes se restringe de modo considerable, al estar en juego la vida y la seguridad, para reivindicar, promover y dinamizar procesos que trasciendan del escenario interno de la empresa al de sindicalismo político, con el fin de incidir en los problemas nacionales que afectan la sociedad civil. En la violencia contra sus dirigentes, el sindicalismo ha encontrado la principal barrera para ser agente relevante en las decisiones nacionales y, por tanto, se 
ha marginado a la representación básica que gira en torno a la fábrica y a reivindicaciones económico-salariales y contractuales. La estrategia de dejar acéfalas y sin plataforma social a las organizaciones sindicales, con el propósito de generar rupturas y debilitar sus procesos organizativos, persiste y trasciende los derechos humanos — vulneración de la vida y la seguridad - a derechos civiles y políticos, al impactar sobre las organizaciones políticas y sus programas de acción social ${ }^{4}$ (Herrera, 2008).

Cuatro factores marcaron significativamente el panorama laboral y sindical de este período.

En primer lugar, las reformas laborales, acuñadas principalmente en la Ley 789 del 27 de diciembre de 2002, que lejos de producir impactos positivos en el empleo se tradujeron en precarización para los trabajadores y altas ganancias para los grandes empresarios. En segundo lugar aparece la política de Seguridad Democrática, que nuevamente ubicó a los sindicalistas en la orilla de los enemigos sospechosos de la seguridad nacional observándolos y tratándolos como posibles subversivos, y que se tradujo en allanamientos ilegales, detenciones y montajes legales contra altos dirigentes sindicales. En tercer lugar, el plan de desmovilización y reinserción de los paramilitares y los procesos de Justicia y Paz, que suponían una cesación de hostilidades, se transformó en una imagen publicitaria de buenos resultados estadísticos y terror desplegado tácticamente; los grupos paramilitares, lejos de detener su acción antisindical, recrearon nuevas estrategias que desvirtuaban y camuflaban las mismas violaciones. En cuarto lugar, el descubrimiento de las siniestras alianzas entre organismos del DAS y grupos paramilitares para asesinar sindicalistas y las aterradoras prácticas materializadas en varios asesinatos de dirigentes sindicales, confirmaron las denuncias y los temores ampliamente dados a conocer por los líderes sindicales colombianos y puso al descubierto la temible conducta antisindical de algunas instituciones del país (Correa, 2007, p. 22).

\footnotetext{
4 Puede verse Confederación Sindical Internacional.
} 
Las prácticas de protesta de los movimientos sociales y sindicales tienen como función actuar sobre la raíz de los problemas derivados de un Estado ineficiente o de la concentración del capital. Por eso, los posibles usos alternativos del Derecho solo serán útiles en tanto sean expresión de una nueva forma de justicia global que cuestione y limite el poder de una élite económica y política con frente a las mayorías. Ahora bien, "las relaciones de poder y los efectos de las desigualdades se formalizan en el terreno político y jurídico, por lo que el uso del Derecho como instrumento contra-hegemónico supone cuestionar las concepciones dominantes de la justicia" (Hernández y Ramiro, 2009, p. 233).

$\mathrm{Al}$ respecto, es fundamental considerar los espacios globales, nacionales y locales desde perspectivas normativas, al igual que desde mecanismos sociales y sindicales para el control de las empresas transnacionales que desbordan los límites regulatorios de los Estados —el imperativo de la regulación internacional para los mercados internacionales es impostergable-. Cada vez se hace más necesario el desarrollo de las reivindicaciones de mayor control democrático de las instituciones financieras y comerciales internacionales, de los tratados de comercio y las inversiones regionales y bilaterales, de las legislaciones nacionales y de las infraestatales. El uso alternativo implica, a su vez, la promoción y defensa de legislaciones internacionales de derechos humanos, de legislaciones nacionales en el marco de la soberanía nacional y de regulaciones de ámbitos no estatales (Hernández y Ramiro, 2009, p. 233).

Por el modo en que las empresas trasnacionales utilizan el Derecho duro (lex mercatoria), blando (códigos de conducta y RSC) y frágil (Derecho Internacional de los Derechos Humanos) según los beneficios que le reporta cada uno, debe ser denunciado y revertido por los movimientos sociales y sindicales [...]. De ahí que las propuestas alternativas para el control de las multinacionales no deban ser un asunto exclusivo de despachos de abogados, ni de expertos en cuestiones internacionales: son, fundamentalmente, propuestas de la ciudadanía (Hernández y Ramiro, 2009, p. 233). 
Los procesos de resistencia política desarrollados por agremiaciones sociales y sindicales se ocupan con mayor vehemencia de frenar las acciones de organismos financieros como el Fondo Monetario Internacional (FMI), el Banco Mundial, la Unión Europea y el G 8, en el ámbito de los países del primer mundo. No obstante, en América Latina las preocupaciones se centran en el papel y efecto de las multinacionales y de los tratados de libre comercio y se logra en diferentes momentos y lugares, intervenir y revertir decisiones que agreden la soberanía de los pueblos, las comunidades y las Naciones. En estas determinaciones han ganado relevancia y poder las movilizaciones sociales y sindicales y las presiones políticas, ya sea por afectación directa o por solidaridad ante otros grupos humanos afectados por las acciones promovidas desde el capital, con lo que se reivindica uno de los valores históricos del sindicalismo: la solidaridad. Este tipo de comportamiento desde la dirigencia sindical demuestra su papel político al activar su estructura en procura del bienestar social que excede los límites y las preocupaciones de la fábrica o de la relación contractual, en procura de construir un modelo de sociedad diferente, aun cuando las resistencias encontradas en los Gobiernos y las instituciones económicas mundiales por conservar la ortodoxia neoliberal sea férrea y sostenida por los medios de comunicación que, como empresa, están condicionados por su vínculo con la financiación privada que los enriquece.

Las organizaciones sindicales siguen reivindicando una legislación estatal más protectora de los derechos, aunque las empresas trasnacionales evitan las regulaciones estatales. De ahí la necesidad de activar un Derecho Laboral supranacional con capacidad vinculante, que fortalezca el papel de la Organización Internacional del Trabajo (OIT) y sus diversos convenios y que validen las cláusulas sociales en los tratados de libre comercio. Sin embargo, esto no resuelve o modifica la estructura económica internacional de la Organización Mundial del Comercio (OMC), los planes de ajuste del Fondo Monetario Internacional (FMI) ni del Banco Mundial (BM), que busca imponer la libertad de capitales sin alguna norma que los regule, el pago de la deuda externa y la inexistencia de gravámenes fiscales a la movilidad de las empresas trasnacionales. "Es determinante que si se quiere 
condiciones laborales justas no puede separarse de la modificación radical de las reglas económicas y financieras globales" (Hernández y Ramiro, 2009, p. 42).

En este campo se sugieren estrategias desde el movimiento sindical: a) la denuncia pública y política de aquellos Gobiernos donde residen las casas matrices de las multinacionales, pues por acción u omisión es el espacio donde se posibilitan las condiciones para el desarrollo de sus actividades con plenas garantías económicas y jurídicas. Es claro que los sindicatos de estas empresas deben trascender su negociación colectiva, al punto de exigir responsabilidades jurídicas a tales Gobiernos, con el objeto de rectificar sus posiciones políticas en los tratados bilaterales; b) ofrecer a las organizaciones sindicales y los movimientos sociales de los países destino de las multinacionales todo el respaldo y reconocimiento frente a las denuncias de políticas neoliberales que aplican los Gobiernos; c) presionar a favor de normas internacionales específicas que incidan en responsabilidad legal de estas empresas — exigibilidad jurídica, creación de un tribunal internacional con capacidad vinculante ante las transnacionales que se diferencie de los mecanismos internacionales existentes, tal es el caso del Derecho Internacional del Comercio con normas imperativas, coercitivas y sancionatorias que actúan en el marco del Banco Mundial, y d) establecer redes entre los dirigentes sindicales en el ámbito internacional donde haya casa matriz, sucursales, filiales o subcontratadas de las multinacionales con el objeto de impulsar acciones en torno a las negociaciones colectivas, apoyo a la libertad sindical, huelgas y acciones en clave de la responsabilidad legal de sus empresas ${ }^{5}$ que trasciendan el ámbito del trabajo y se relacionen con la sociedad en general, frente a la afectación al ambiente, a las comunidades indígenas y los derechos humanos y laborales. Estas estrategias fueron sancionadas en 2008 por el Tribunal Permanente de los Pueblos (TPP).

\footnotetext{
5 TPP Capítulo Colombia se inició en marzo de 2006 y finalizó en julio de 2008. En los tres años que duró el proceso se juzgó a las multinacionales según sus sectores de actividad: alimentación, minería, biodiversidad, petróleo, servicios públicos, pueblos indígenas y audiencia deliberativa final.
} 
El Tribunal considera que hay fundamentos razonables para calificar una gran cantidad de los actos concretos de asesinato, masacre, tortura, desplazamiento forzoso de población y persecución, que le han sido presentados como crímenes de lesa humanidad, en la medida en que han sido cometidos de manera sistemática y generalizada, contra la población civil [...] además, los Tribunales de los Pueblos muestran cómo los gobiernos de los países periféricos se sometieron a las imposiciones neoliberales, para lo cual aceptaron los chantajes del FMI y BM, desregularizaron los derechos sociales, privatizaron sus empresas estatales y los servicios públicos y, por decirlo de manera sencilla, reformaron el Estado. Y, por su parte, los gobiernos de los países donde las corporaciones tienen su sede matriz han demostrado que se identifican al cien por cien con sus empresas multinacionales: las apoyan política y económicamente y defienden sus privilegios en las instituciones internacionales, dejando de lado los derechos de las mayorías sociales del planeta (Hernández y Ramiro, 2009, p. 249).

En previsión de lo anterior, se adelantaron en la década del ochenta los procesos educativos ${ }^{6}$ en materia sindical en el país por medio de organizaciones propias del sindicalismo o de organizaciones alternas desde la sociedad civil como la Escuela Nacional Sindical (ENS). Esta organización, cuya existencia se remonta casi tres décadas, se concentra en la investigación, asesoría y divulgación de los procesos del mundo del trabajo, en particular, del desarrollo del sindicalismo en Colombia, así como de sus formas organizativas, fortalecimiento interno, expresión internacional y transformación política. Al respecto,

\footnotetext{
6 "En los inicios de la ENS actuaban otros centros de formación: el Colegio Laboral colombiano que servía de apoyo a la UTC y la CTC; el INES cubría las necesidades de formación y asesoría de los sindicatos de la CGT; el INS a un sector del sindicalismo independiente y el CEIS a los sindicatos influenciados por el Partido Comunista y agrupados en la CSTC. También actuaban sin relación orgánica o dependencia sindical el ISMAC, el CINEP y el IPC. En los centros de formación de relación política u orgánica con centrales o agrupaciones sindicales predominaban prácticas acordes con sus características políticas: en las centrales sindicales tradicionales, una formación centrada en el código del trabajo y en la formación de líderes con capacidad retórica, por ello eran muy frecuentes los cursos de oratoria. El abogado era el centro de la formación, como lo era en la negociación de los pliegos de peticiones" (Ríos, 2007, p. 51).
} 
Norberto Ríos, quien fuera uno de sus fundadores y director en diferentes momentos, expresa rasgos centrales del sindicalismo colombiano para el momento en que se disputaba entre el gremialismo, el apoliticismo y el maximalismo político.

Al inicio de la década del ochenta ya se habían consolidado dos corrientes distintas en el sindicalismo colombiano. Una de ellas respondía a la idea de sindicalismo que quería el empresariado o sindicalismo patronista y los partidos políticos tradicionales, cuyos rasgos centrales estaban consignados en la Constitución y las normas laborales:

[...] un sindicalismo pensado para actuar solo en el marco de la empresa y de los intereses económicos-gremiales de los trabajadores; predominaba el sindicato y la negociación colectiva por empresa; prohibición de la participación política de los sindicatos (salió de la Constitución en 1991) y un discurso reiterado e interiorizado por las dirigencias sindicales tradicionales de apoliticismo, estos rasgos se complementaban con una dirigencia mayoritariamente supeditada a la lógica e intereses de los empresarios, el Estado y los partidos liberal y conservador. La otra corriente sindical, de izquierda, respondía a un ideario marxista y revolucionario con fuerte dependencia de los partidos de la izquierda en Colombia y de los centros políticos del socialismo en el mundo: Unión Soviética, China y Cuba. Era un sindicalismo profundamente ideologizado, que se agrupaba de manera informal por afinidades ideológicas y partidistas que no se consideraba incluido en el Estado colombiano, por ello se resistía a cualquier participación en sus instituciones, incluidas las del órgano legislativo, no por casualidad esgrimía un exacerbado y activo abstencionismo. Concebía su protagonismo político como fuerza contestataria que impulsaba acciones tendientes a destruir el orden económico social vigente, el Estado y los partidos políticos tradicionales, en procura de instaurar el socialismo en el país y el poder hegemónico del proletariado (Ríos, 2007, pp. 50-51).

Este sindicalismo desarrollaba una intensa acción reivindicativa como medio de acción política en el espacio de la empresa, con un fuerte 
discurso de lucha de clases; aunque ambas corrientes padecían dos males comunes: división ideológica y organizativa y dependencia orgánica o política de partidos o grupos políticos.

En perspectiva, la modernización de este actor social, correspondiente al cambio de la cultura política, es progresiva, sistemática y ascendente.

Si bien es cierto que el sindicalismo colombiano tiene hoy menos peso cuantitativo que en 1982, producto de múltiples factores: una agresiva política empresarial, con apoyo gubernamental, de relaciones laborales sin sindicato y sin convenio colectivo, la violencia antisindical y la flexibilización laboral, entre otras, su centralización es mayor y su protagonismo político es más significativo en los escenarios laborales e institucionales (Ríos, 2007, p. 53).

Reconoce que, dentro de los avances en materia política del sindicalismo, a) hoy existen tres centrales sindicales, una de ellas, la CUT, que agrupa cerca de $60 \%$ de los sindicalizados del país; b) los sindicatos que están por fuera de alguna orientación o asociación nacional no llegan a 20\% de los afiliados; c) hoy predomina la política de actuación en todos los escenarios de la institucionalidad del país y su preocupación por los asuntos de la Nación, expresados en los planes de desarrollo nacionales y locales, es cotidiana; d) su objetivo de crear poder desde la orilla de los trabajadores es cada vez más extendida; ello se evidencia en la casi inexistencia de políticas activas de abstencionismo como fue claramente manifiesto en otro tiempo, y e) hoy:

[...] casi todas las corrientes políticas en el sindicalismo participan en los procesos electorales y son múltiples y notables los exdirigentes sindicales que ocupan cargos como autoridades locales o en cuerpos colegiados, baste sólo decir, que de los diez senadores del Polo, siete son de origen sindical y su elección se dio por el apoyo muy significativo de ciudadanos sindicalizados (Ríos, 2007, p. 53).

Al igual que en el departamento de Valle del Cauca con Angelino Garzón como exgobernador y en Bogotá con Luis Eduardo Garzón en la 
anterior Alcaldía, el partido político Polo Democrático y su electorado nombraron en cargos de representación a exdirigentes sindicales de reconocida trayectoria en la dirigencia de la CUT. De igual manera, en otras ciudades se hizo manifiesto el acercamiento entre la dirigencia sindical y las elecciones populares de alcaldes, concejales, ediles y diputados respaldados por tal partido (Magil, 2004, p. 265).

El discurso de participación política, centrado en el papel de los dirigentes sindicales como responsables ciudadanos en los destinos del país y de las localidades no solo dirigentes en los espacios de trabajo- , son llamados a conocer y a hacer propuestas desde los trabajadores y a ganar mayor protagonismo social y político, al contribuir con otras iniciativas al cambio en la cultura política en el sindicalismo y en sus dirigentes; es también una preocupación promovida desde la modernización del sindicalismo que camina a su accionar como actor político unificado, fortalecido y con mayor capacidad política (Ríos, 2007, p. 53). Ahora, en términos de las preocupaciones educativas y de formación de los dirigentes sindicales y sus estructuras, en la actualidad el sindicalismo se acompaña de una oferta temática que cubre la formación técnica — mecánica sindical— que supera lo jurídico en la formación política y a la doctrina marxista, con profundización de las políticas contemporáneas, formas históricas del sindicalismo, economía política, historia obrera, economía colombiana, Derecho Laboral, Derecho colectivo de trabajo, salud ocupacional, comunicación, conquistas laborales colectivas en la gran industria colombiana, aspectos subjetivos del trabajo y participación política, entre otros.

Sin embargo, en sectores todavía muy atrasados de la sociedad, pero especialmente en personas interesadas en retener a las masas trabajadoras en condiciones de sumisa inferioridad, se oye con frecuencia el viejo estribillo de que los sindicatos no pueden participar en política [...]. Los jefes oligarcas de los partidos en Colombia desean un movimiento sindical sin política laboral, un movimiento sindical que no se mueva, un movimiento sindical que no les quite votos, por eso arengan el "apoliticismo" (Rodríguez, 2005, p. 30). 
En el marco de los lineamientos del sindicalismo internacional, en el $2^{\circ}$ Congreso mundial de la CSI:

[Se] afirma que el propósito de los sindicatos es defender y promover los intereses de los trabajadores, que esto no puede llevarse a cabo sin organizarlos, y que sólo por medio de su propia organización podrán cambiar el mundo del trabajo, crear una sociedad más justa y conseguir plenamente el trabajo decente [...] les permiten estar defendidos y representados, y expresar sus opiniones respecto a los asuntos públicos y en las negociaciones colectivas. Por otro lado, la capacidad de los sindicatos para cumplir su propósito depende de su fuerza, capacidad de movilización y legitimidad, que provienen exclusivamente de su membresía (Confederación, 2010, p. 2).

En clave del papel del sindicalismo, se les exige una participación decidida, clara y planificada en las esferas de la política electoral a partir de un sindicalismo político.

El $2^{\circ}$ Congreso mundial de la CSI declara que los sindicatos deben cambiar para adaptarse a nuevas situaciones y que tales cambios resultan inevitables y necesarios. Además, deben reflejar las necesidades diversas y cambiantes de los trabajadores. Un movimiento sindical capaz de atraer miembros debe propiciar la participación, representatividad, diversidad e integración de cuestiones de género. Las organizaciones sindicales deben analizar sus métodos y procedimientos de trabajo, con objeto de determinar si convendría ajustar sus estructuras o crear nuevas para brindar representación a todos los grupos de trabajadores, incluidos los menos privilegiados y aquellos con relaciones de trabajo informales. Las relaciones existentes entre los distintos tipos de organizaciones sindicales — nacionales, regionales y locales, industriales o empresariales - han de adaptarse para garantizar la democracia, la autonomía y la sostenibilidad de un movimiento sindical en progresión y que cuente con una asignación óptima de recursos para la negociación y organización (Confederación, 2010, p. 5b). 


\section{Algunas conclusiones}

Los censos sindicales realizados en el país indican que históricamente el sindicalismo colombiano ha estado influenciado en lo político, en su mayoría, por las corrientes de izquierda, más que por el sindicalismo patronista, lo que implica una concepción del Estado esencialista o asistencialista. Así, el sindicalismo ha concentrado sus fuerzas en las reivindicaciones fabriles, sin involucrarse en la democratización de la sociedad y en las preocupaciones macrosociales y macroeconómicas, es decir, en esencia es un sindicalismo confrontador antes que negociador, lo que le ha significado la exclusión de los escenarios de decisión política nacional, al igual que al sindicalismo patronista que halla en su empleador a su defensor, protector y amparo, evita incluir en su lucha necesidades sociales por fuera de su núcleo de trabajo. Ambas corrientes sindicales — patronista y de izquierda-, como Santana (1989) afirma:

$[\ldots]$ han tenido una influencia decisiva para mantener al movimiento sindical alejado de los problemas de la población, por ejemplo de las luchas cívicas, urbanas, por la vivienda, por la cultura, etc., [sic] y esto ha conducido a un aislamiento paulatino del movimiento sindical de los restantes movimientos populares, confluencia que es decisiva para la trasformación democrática de la sociedad (p. 216).

El movimiento de los trabajadores en la historia del país ha tenido, según han planteado diversos investigadores, poco peso social y político. Además de lo anterior, han contribuido factores como la división ideológica interna, el desconocimiento sobre los cambios necesarios en el país, el aislamiento de otros sectores sociales y el peso de una concepción que, hasta años muy recientes, redujo la lucha de los trabajadores a la reclamación salarial en su sindicato de base. Otra causa es la relación difusa con sus correlatos políticos, esto es, con partidos y movimientos políticos, por cuanto sus relaciones con la izquierda no son uniformes y con los Partidos Liberal y Conservador son distantes. 
El tipo de modernización que requiere el sindicalismo debe contemplar algunas características como el diseño de los planes y estrategias, de acuerdo con los intereses y las necesidades de los trabajadores en un ambiente de disertación y debate que permita la reflexión. Debe ser una modernización integral que considere los avances del sindicalismo progresista y que asuma los retos de la construcción de ciudadanía; además, debe recuperar tradiciones positivas del movimiento sindical como la solidaridad y la identidad social y cumplir con su papel de actor político que regule poder, en esencia, poder político (Giraldo 1994, p. 123).

En Colombia el sindicalismo y, en general, el movimiento social de los trabajadores ganará terreno en las arenas de la representación electoral o terminará convertido en una masa amorfa anclada en la informalidad, sin dirigentes o plan programático, de espalda a la sociedad sin representar los intereses sociales, incomunicada con las corrientes internacionales y enmudecida ante el Gobierno y los gremios económicos y empresariales, quienes procuran que haya cada vez más masa de trabajadores y menos organizaciones sindicales estructuradas como opción democrática que fortalezca el Estado Social de Derecho. Fruto de ello ha sido la tendencia en la última década de un sindicalismo desvanecido como colectividad y representado individualmente por algunos dirigentes en pocos escenarios de toma de decisión.

\section{Referencias bibliográficas}

Bartolini, S. (1988). Manual de ciencia política. Madrid: Alianza.

Bernal Medina, J. A., y Álvarez Castaño, L.S. (2005). Democracias y ciudadanías. Balance de derechos y libertades en Medellin. Medellín: Corporación Región, Corporación Viva la Ciudadanía, Escuela Nacional Sindical, Confiar Cooperativa financiera.

Bobbio, N. (1986). El futuro de la democracia. México D. F.: Fondo de Cultura Económica.

Bobbio, N., Matteucci, N., y Pasquino, G. (1993). Diccionario de politica. México D.F.: Siglo XXI.

Calero, A. M. (1985). Partidos políticos y democracia. Barcelona: Salvat. 
Confederación Sindical Internacional [CSI]. (2010). Resolución sobre sindicalización. $2^{\circ}$ Congreso Mundial. Vancouver: CSI.

Correa, G. (2007). Una historia tejida de olvidos, protestas y balas. 21 años de asesinatos selectivos y sistemáticos contra sindicalistas en Colombia 1986-2006.Controversia (188), 171-198.

De la Garza, E. (coord.) (2003). Tratado latinoamericano de sociología del trabajo. México D. F.: Fondo de Cultura Económica.

Giraldo Ramírez, J. (ed.) (1994). Alternativas sindicales para el nuevo milenio. Medellín: Escuela Nacional Sindical.

Giraldo, F. (2003). Sistema de partidos políticos en Colombia. Bogotá: CEJA Centro Editorial Javeriano.

Giraldo, F. (2004). Los partidos y el sistema político colombiano. Desafíos, (11), 160-179.

Gramsci, A. (1985). La política y el Estado moderno. Buenos Aires: Planeta-De Agostini.

Hernández Zubizarreta, J., y Ramiro, P. (eds.) (2009). El negocio de la responsabilidad, crítica de la responsabilidad social corporativa de las empresas trasnacionales. Barcelona: Icaria S.A.

Herrera, E. (2008). Violencia antisindical en Colombia durante el año 2007. Relecturas, (31), 25-35.

López de Mesa, D., y Monsalve, B. (1991). Movimientos sociales urbanos y hábitat: estudio de los movimientos comunal, de adjudicatarios de vivienda, civico y sindical de Fabricato y Coltejer, en Bello e Itagüí, 1982-1986. Medellín: Centro de Estudios del Hábitat Popular.

Magil, M. G. (2004). Crónica oculta del conflicto. Antecedentes, estrategias de pary opiniones de los protagonistas. Bogotá: Ediciones Desde Abajo.

Poveda Ramos, G. (2005). Historia económica de Colombia en el siglo XX. Medellín: Universidad Pontificia Bolivariana.

Ríos Navarro, L. N. (2007). La ENS en la modernización del sindicalismo colombiano. Cultura\& Trabajo, (72-73), 50-56.

Rodríguez Díaz, C. A. (2005). El sindicalismo en un mundo cambiante. Bogotá: CUT.

Sánchez, R. (1994). La organización politica y los sistemas de partidos. Bogotá: Gazeta Ltda.

Santana Rodríguez, P. (1989).Los movimientos sociales en Colombia. Bogotá: Ediciones Foro Nacional por Colombia. Colombia. 
Sartori, G. (1992). Partidos y sistemas de partidos. Madrid: Alianza.

Urrutia, M. (1996). Historia del sindicalismo colombiano. Bogotá: Señal editora.

Warren, M. (2003). ¿Qué es la política? En A. Artete, E. García y R. Gaitán (eds.), Teoría política: poder, moral, democracia. Madrid: Alianza. 